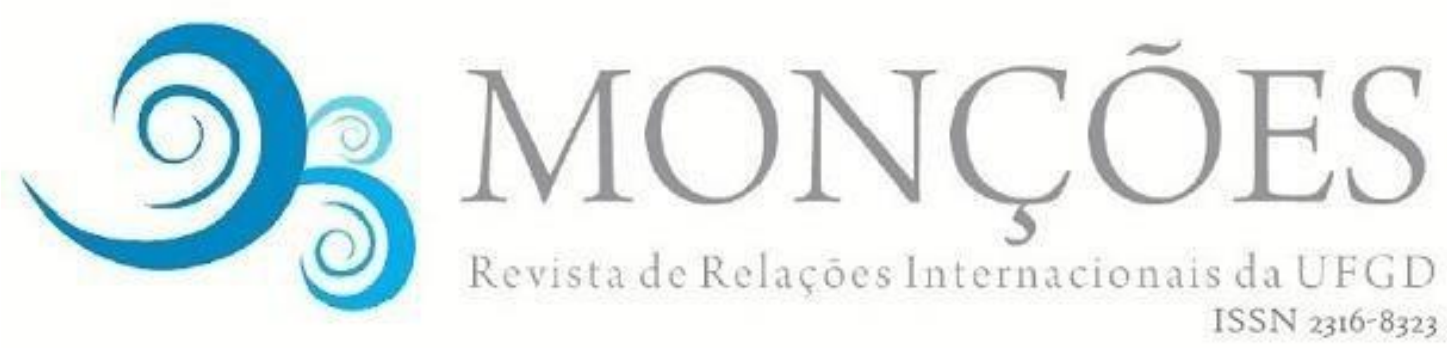

\title{
RELAÇÕES INTERNACIONAIS E ESTUDOS SOBRE SEGURANÇA: AFINAL 'QUEM' OU 'O QUÊ' DEVE SER PROTEGIDO?
}

IURE PAIVA

Doutor em Ciência Política (UNICAMP). Professor do Programa de Pós-Graduação em Ciência Política e Relações Internacionais (PPGCPRI/UFPB) e do Departamento de Relações Internacionais (DRI/UFPB). Coordenador do Grupo de Estudos Sobre Segurança Energética (GESEne/UFPB/CNPq).

\begin{abstract}
RESUMO: Nas abordagens analíticas sobre segurança é recorrente o debate quanto ao objeto referencial a ser tutelado, em outras palavras: saber "quem" ou "o quê" deve ser protegido. Tendo como ponto de partida tal discussão, o presente artigo tem como objetivo expor uma análise pontual sobre as diferentes formas de abordar a questão dos objetos referenciais nos estudos sobre segurança e relações internacionais. A questão-chave a ser esclarecida é a seguinte: quais foram os objetos referenciais evidenciados pelas práticas políticas e captados pelos estudos teóricos-analíticos sobre a matéria? Com base numa extensa revisão da literatura, realizou-se uma análise que considera cinco tipos de abordagem sobre objeto referencial da segurança: (1) as centradas na proteção do Estado; (2) as que protagonizam a tutela do ser humano; (3) as que têm a sociedade como referência; (4) as que consideram o meio ambiente como prioritário; e, (5) as que focam no exame segundo diferentes níveis de análise. Examina-se cada uma das abordagens supracitadas evidenciando o contexto histórico no qual surgem, suas premissas teóricas fundamentais, a natureza e a amplitude dos dilemas de segurança que confrontam, e, por fim, as contestações levantadas pelos críticos que se opõem a cada perspectiva apresentada. O presente artigo pretende assim possibilitar ao leitor aprofundar a compreensão relativa aos limites categóricos sobre como a segurança pode ser definida em termos práticos e teóricos. Além disso, permite o contato com perspectivas analíticas e agendas de pesquisa mais amplas, que enquadram os debates sobre segurança para além da lógica da guerra, da "política de exceção", do emprego de medidas excepcionais e da consecução de objetivos predominantemente político-militares.
\end{abstract}

PALAVRAS-CHAVE: Relações Internacionais; Segurança; Objetos referenciais; Debate Teórico.

\section{INTERNATIONAL RELATIONS AND STUDIES ABOUT SECURITY: AFTER ALL, "WHO" OR "WHAT" SHOULD BE PROTECTED?}

ABSTRACT: In analytical approaches about security is recurring the debate about the referential object to be protected, in other words: "who" or "what" should be protected. From this starting point of discussion, this article aims to expose a thorough and detailed analysis of the different ways of approaching the issue of reference objects in studies about security and international relations. The key question to be answered is: what were the referential objects evidenced by political practices and raised by the theoretical-analytical studies about the subject? Based on an 
extensive literature review, there is an analyze that considers five types of approach to referential object of security: (1) the focus on state protection; (2) those that the protection of the human being is the protagonist; (3) those with society as a reference; (4) those that consider the environment as a priority; and (5) the focusing in the examination using different levels of analysis. Thereafter, each of the above approaches is examined highlighting the historical context in which they arise, their fundamental theoretical assumptions, the nature and extent of the security dilemmas that confront, and finally, the challenges raised by critics who oppose certain aspects presented. This article aims to enable the reader to deepen the understanding concerning the categorical limits about how security can be defined in practical and theoretical terms. It also allows contact with broader analytical perspectives and research agenda that frame the debates on security beyond the logic of war, the "exception policy", the use of extraordinary measures and the achievement of political-military objectives.

KEYWORDS: International Relations; Security, Referential objects; Theoretical debate.

\section{INTRODUÇÃO}

A produção de textos na área de segurança no Brasil não pode ser considerada escassa, já que existem inúmeros trabalhos tratando de diversos aspectos práticos e teóricos sobre a temática, os quais acabam contribuindo na conformação de um profuso referencial analítico sobre a matéria em publicações nacionais. No que se refere a ensaios bibliográficos, que visam oferecer um panorama geral do estado da arte sobre questões específicas no campo da segurança, também é possível encontrar alguns trabalhos, dedicando-se, no todo ou em parte, a essa tarefa.

Nesse sentido, pode-se mencionar trabalhos que visam esclarecer a diferença entre estudos estratégicos, defesa e segurança, de modo a apresentar avanços e controvérsias na tentativa de separação das áreas de pesquisa (RUDZIT, NOGAMI, 2010; SAINT-PIERRE, 2007; MESSARI, 2004). A evolução do conceito de segurança também é objeto de investigações, as quais vão desde uma proposta de constituição de uma "História do Conceito de Segurança", a partir de suas raízes etimológicas aos usos contemporâneos, àquelas um pouco mais restritas, focando nas análises sobre as transformações na sua concepção pós-Guerra Fria (SAINT-PIERRE, 2011; CRAVO, 2009; PUREZA, 2009; AMARAL, 2008). Existem ainda os que examinam o desenvolvimento dos 
estudos na área ao longo dos tempos, cujo marco inicial remonta ao pósSegunda Guerra Mundial, com investigações centradas em discutir os desafios de manter a segurança nacional contra ameaças militares e externas, alcançando as pesquisas mais recentes, as quais se caracterizam pelo enfrentamento de novas e amplas agendas, contextos, ameaças e atores (PAIVA, 2015; BARBOSA, 2012; VILLA, REIS, 2006; RUDZIT, 2005). Além disso, têm-se ainda os que avaliam as diferentes "escolas de pensamento" que se constituíram nos estudos de segurança, buscando identificar sua gênese, fundamentos conceituais, teóricos e analíticos, convergências e divergências na abordagem de problemas comuns, aspectos normativos imanentes e contradições, bem como sua contribuição para o avanço das análises e das ações domésticas e internacionais sobre o tema (DIAS, MOTA, RATINO, 2011; AZEVEDO, 2009; DUQUE, 2009; TANNO, 2003).

No entanto, verifica-se a ausência de ensaios bibliográficos no país com uma abordagem ampla e aprofundada tendo como base os objetos referências da segurança, ou seja, compreender em que medida as diferentes discussões que surgiram em torno daquilo que deve ser protegido no âmbito das medidas de segurança, repercutem na delimitação do seu conceito, na orientação das análises e na conformação das ações políticas em diferentes contextos. De modo geral, seja nos estudos supracitados como em outros tantos presentes na literatura nacional, observa-se que a referida temática é recorrentemente mencionada em meio à diversidade de aspectos analisados, mas sem figurar como tópico central. O que, de certa forma, causa certa espécie, dada a relevância do assunto, pois na ausência de um objeto referencial não pode haver discussões sobre segurança, visto que o seu conceito não faz sentido sem algo a ser protegido (WILLIAMS, 2008, p.7). Em outras palavras, na abordagem analítica sobre segurança é de fundamental importância determinar de modo claro qual o seu objeto referencial: saber "quem" ou "o quê" se pretende proteger.

Essa lacuna na literatura brasileira, de certa forma, pode limitar a compreensão que as discussões sobre objetos referenciais vêm produzindo no desenvolvimento de estudos teóricos e na formulação de políticas na área da segurança. Essa carência de trabalhos sobre a matéria pode gerar ainda uma 
falsa percepção de que os objetos referenciais são livres de embates conceituais e analíticos entre distintos autores e correntes teóricas, ou não são alvo de críticas e controvérsias entre diferentes atores sócio-políticos, tanto na esfera nacional como internacional. Uma virada nesse panorama parece ser assim necessária, sendo o propósito deste texto, contribuir de alguma forma para superar a referida carência nas publicações brasileiras.

Diante do cenário ora descrito, o presente texto presta-se, antes de tudo, a colaborar com a ampliação dos trabalhos produzidos no Brasil na forma de ensaio bibliográfico, que abordem questões teóricas e práticas controversas no campo da segurança. Para tanto, apresenta nas páginas seguintes uma síntese das diferentes formas de abordar a discussão sobre os objetos referenciais da segurança, tendo como base uma revisão da literatura nacional e internacional sobre o tema. Há, pelo menos, duas questões-chave a serem esclarecidas neste artigo: Quais foram os objetos referenciais evidenciados pelas práticas políticas e captados ao longo da história nos estudos sobre segurança? E, em que medida as diferentes abordagens, efetivamente, implicaram em mudanças de ordem conceitual e analítica sobre segurança?

De modo a encontrar respostas para as questões supracitadas, na análise realizada considera-se a classificação dos objetos referenciais proposta por Williams (2008, p.7), a qual identifica cinco linhas de abordagem: (1) a perspectiva tradicional, que está centrada no Estado; (2) a que sustenta a ideia de "segurança humana"; (3) aquela que tem a "sociedade" como principal referência das medidas protetivas; (4) a que considera o meio ambiente como elemento prioritário a ser protegido; e, (5) a que se fundamenta na percepção de diferentes níveis de análise na orientação dos objetos a serem resguardados.

Nas páginas seguintes, para cada uma das cinco diferentes linhas de abordagem são apresentados o contexto histórico em que emergem, os argumentos teóricos basilares que as sustentam, a respectiva natureza e amplitude dos dilemas de segurança que evidenciam, bem como as limitações e contestações comumente levantadas pelos críticos que se opõem à determinada forma de tratamento do assunto. Em meio a todos esses fatores examinados, 
demonstra-se de que modo as diferentes perspectivas sobre objetos referenciais influenciaram na concepção da segurança em termos conceituais e analíticos, incluindo a ação governamental sobre a matéria.

Vale ressaltar que não se pretende definir que os estudos sobre segurança deveriam levar em conta todos, uma parte ou apenas um dos objetos referenciais expostos mais adiante, mas apresentar a forma como o tema pode ser trabalhado no nível teórico e prático. Da mesma forma, é importante advertir que as respostas às questões acima mencionadas têm a contribuir, não apenas, para o estabelecimento dos limites categóricos sobre como a segurança é definida, mas também evidenciar que tipos de projetos de investigação e análise são realizados em torno da matéria em apreço. Cabe destacar ainda o compromisso deste texto em possibilitar ao leitor contato com perspectivas teóricas e agendas de pesquisas que distanciam a segurança da lógica da guerra, da "política de exceção", do emprego de medidas excepcionais e da consecução de objetivos predominantemente político-militares. Esse objetivo se justifica pela necessidade de refletir e ir além/superar tal visão predominante sobre segurança, comumente, defendida por autores das correntes tradicional (WALT, 1991; WALTZ, 1979) e neoclássica-setorial (BUZAN et al., 1998; WÆVVER et al., 1993). Em certa medida, isso pode reforçar a relevância deste artigo, dada a necessidade de ampliar a percepção dos estudiosos e pesquisadores brasileiros sobre as questões supracitadas.

Além desta introdução, o presente texto conta com mais cinco seções. A próxima seção discorre sobre o Estado como principal objeto referencial da segurança, elemento característico das abordagens (neo)tradicionais, nas quais predominam uma visão estado-centrista que enviesa a concepção de vários aspectos sobre a temática. No terceiro momento, considera-se a proteção do ser humano como foco primordial das medidas de segurança, evidenciando a ampla transformação que esse ponto de vista causa no tratamento da temática, bem como sua vasta aceitação nos círculos acadêmicos-científicos e políticoinstitucionais. A proteção de certos valores e demais condições de desenvolvimento de uma sociedade tornam-se o foco das análises na quarta 
seção, evidenciando controvérsias sobre a determinação de seus limites categóricos e conflitos entre interesses estatais e de alguns grupos nacionais.

A quinta seção traz à tona a possibilidade de o meio ambiente natural e humano ser o componente protegido, expondo não apenas os desafios relativos à promoção de sinergia entre progresso e sustentabilidade, mas também as constantes polêmicas quanto à ampliação do significado de segurança decorrentes do debate sobre a necessidade ou não de admitir um elenco cada vez maior de objetos referenciais. Na penúltima seção considera-se a proteção de unidades políticas específicas, indo desde a salvaguarda do indivíduo à manutenção das condições de subsistência em âmbito global, permitindo assim melhor compreender as demandas de cada estrato, e entender a dinâmica das práticas governamentais e intergovernamentais nos diferentes níveis. Na última seção, as considerações finais apresentam uma síntese conclusiva sobre alguns aspectos relativos à segurança que foram levantados e analisados ao longo deste artigo a partir das controvérsias envolvendo os objetos referenciais.

\section{O MODELO TRADICIONAL DE ANÁLISE: O QUE IMPORTA É A PROTEÇÃO DO ESTADO?}

Conforme ressaltam Buzan e Hansen (2009, p.11), desde os estudos iniciais sobre segurança, cujo marco costuma ser o final da Segunda Guerra Mundial, é perceptível que a proteção do Estado se evidencia como o principal objeto referencial nos debates sobre segurança nacional e internacional ${ }^{1}$. A consolidação dessa perspectiva, segundo aqueles autores, contribuiu para a conformação da ideia de que a segurança do Estado implicaria na melhor forma

\footnotetext{
${ }^{1}$ Buzan \& Hansen $(2009$, p. 11) chamam a atenção para o fato de que o termo mais apropriado seria "segurança do Estado", uma vez que o conceito de "segurança nacional" consistiria na fusão da segurança do Estado com a segurança da Nação, o que implicaria em reconhecer que a "[...] nação apoiou um Estado poderoso que retribuiu lealmente com a proteção dos valores e dos interesses da sua sociedade". Paul D. Williams (2008, p. 11) defende igualmente o emprego da expressão "segurança do Estado", por considerar que "[...] muitos Estados eram muitas vezes hostis a nacionalidades específicas presentes em suas fronteiras".
} 
de proteger outros objetos referenciais, tais como o indivíduo, os grupos étnicos, o meio ambiente e o próprio planeta. É importante ressaltar que essa concepção se tornou predominante tanto entre os estudiosos da área, como os formuladores de políticas em distintas instâncias de decisão, influenciando as reflexões e iniciativas governamentais, seja no âmbito das relações domésticas ou internacionais.

Em meados do século XX, Wolfers (1952, p. 481-2) já destacava que a segurança era cada vez menos direcionada à satisfação de necessidades individuais, grupos subnacionais, da "quimérica comunidade internacional" ou da humanidade, e mais dirigida a atender, eminentemente, às demandas estatais, enfatizando assim que a política nesse domínio subordinava os demais interesses àqueles do Estado. Contribui para a constituição desse panorama, o fato de as questões militares ocuparem espaço predominante na configuração do "interesse nacional" em grande parte do mundo, não obstante a relevância dos interesses socioeconômicos. Nesses anos, conforme o referido autor, ocorria uma mudança da interpretação do bem-estar (welfare) para a defesa (security) como o símbolo do interesse nacional. Essa tendência encontrou nos autores da corrente realista clássica das Relações Internacionais um forte amparo (CARR, 2002; MORGENTHAU, 2003; ARON, 2003). Nesse sentido, Carr (2002, p. 252) destaca, por exemplo, que "Nas relações internacionais, 0 acordo político tende a se restringir às esferas que não afetam a segurança e a existência do Estado", ressaltando a preponderância que o ente estatal possui sobre os demais objetos a serem protegidos.

Durante a Guerra Fria a literatura na área de segurança persistia em identificar, predominantemente, como principal objeto de análise e das ações a proteção do Estado, motivada pela disputa entre as duas grandes potências vencedoras da Segunda Guerra (Estados Unidos e a União Soviética), a qual foi marcada pela possibilidade de conflitos armados e pela expansão dos investimentos militares, das armas nucleares e da tecnologia bélica em geral. $O$ caráter estado-centrista permanecia nos estudos sobre segurança e se manifestava também na noção de que segurança é uma questão inerente ao Estado e ao Estado cabe tratar dessa matéria (BUZAN et al., 1998, p. 37). Ao 
longo da Guerra Fria, o protagonismo da teoria neorrealista (WALTZ, 1979; JERVIS, 1976) era apontado como um dos fatores que contribuíram para a prevalência de tais dogmas nas relações internacionais e na concepção da segurança, influenciando tanto o campo de estudo como as ações políticas. $\mathrm{Na}$ visão de Smith (1999, p. 74), na medida em que o neorrealismo atribuiu papel central à estrutura do sistema internacional, os estudos sobre segurança passam a se concentrar ainda mais nos Estados, na disputa pelo poder e nos conflitos militares.

Do mesmo modo, no cenário que emergiu a partir do fim da Guerra Fria, na visão de (neo)realistas contemporâneos como Mearsheimer (2005), a competição por segurança em termos tradicionais e a guerra entre as grandes potências não deu lugar à cooperação, pois todos ainda se preocupavam em ganhar poder, os Estados ainda temiam uns aos outros e a anarquia igualmente persistia. Como não houve alteração estrutural, continua o autor, não haveria nenhuma mudança de comportamento, e esse cenário não se alterou porque ninguém queria abrir mão de "ser um Estado", e porque o nacionalismo permaneceu como uma das mais poderosas forças políticas no mundo. Segundo ressalta Booth (2007, p. 35-36), os (neo)realistas contemporâneos ainda têm uma forte tendência a negligenciar outros objetos referenciais de segurança que não sejam os entes estatais, e a conformar um certo tipo de ética hostil aos interesses humanos, colocando, costumeiramente, o "monstro frio" do Estado no centro do debate.

De acordo com Munster (2005, p. 2), o pensamento tradicional sobre a segurança foi desafiado por aqueles que criticaram a abordagem (neo)realista centrada no Estado, e o privilégio dado a este objeto referencial em específico é insuficiente para resolver problemas de segurança "comum" ou "humana", que necessitam de uma reflexão sobre o nível do indivíduo, dos subgrupos estatais ou no nível da humanidade como um todo. Já Jones (1996, p. 209) afirma que alguém que se concentra em analisar outros objetos referenciais da segurança que não o Estado, perceberá de imediato que as ameaças existenciais a esses referentes - sejam indivíduos, nações e outros - são muito mais amplas do que aquelas representadas pela força militar. 
Nesses termos, conforme as palavras de Walker (2007, p. 155), "No mundo moderno, os Estados têm conseguido mais ou menos monopolizar nossa compreensão do que é a vida política e onde ela ocorre", e, dessa forma, continua o autor, "A segurança dos Estados domina a compreensão sobre o que a segurança pode ser e a quem pode se dirigir, não porque o conflito entre os Estados é inevitável, mas porque outras formas de comunidades políticas são consideradas quase como impensáveis". A segurança dos Estados conformase, portanto, como elemento basilar na concepção tradicional sobre segurança, evidenciando, entre outras questões, a quem devem ser dirigidas as ações nesse domínio, abordagem amplamente respaldada pelos autores (neo)realistas. Assim sendo, as ações a serem implementadas e o foco das análises recaem na preservação da soberania nacional e integridade territorial, ocupando o topo na hierarquia dos objetivos a serem alcançados no âmbito da segurança.

Os debates sobre segurança, nos termos ora expostos, incorporariam assim uma visão centrada no estatismo e no estado-centrismo, que representariam o caráter normativo e analítico do denominado modelo tradicional dos estudos sobre segurança. O estatismo seria uma posição normativa fundamentada na ideologia de que toda lealdade e poder de decisão repousam e estão concentrados no Estado soberano, não havendo outro que the fosse superior ou maior, sendo, portanto, o objeto referencial e agente fundamental da segurança (BOOTH, 2007, p. 34). Em contraposição ao estatismo estariam os padrões de governança global, que envolveriam a complexa descentralização no nível infra estatal e a presença de organizações funcionais no nível supra estatal, conformadas pela crescente interdependência econômica, social e cultural no âmbito da sociedade civil nacional e transnacional, concorrentemente ou complementarmente ao poder efetivo dos governos nacionais (BOOTH, 1998, p. 343).

Já o estado-centrismo representaria uma escolha teórico-analítica, que consiste em tratar o Estado como o ator central na política mundial, e em concentrar em suas práticas os estudos sobre os fenômenos internacionais (BILGIN, 2005, p. 94). Esse tipo de abordagem é frequentemente justificado na literatura corrente como uma escolha metodológica que visa adequar os estudos 
em Relações Internacionais ao modelo das ciências naturais. Uma tentativa de imprimir caráter "científico" às análises sobre política mundial, criando para tanto um "sistema fechado", que identificaria no Estado o ator principal, concebido como unidade analítica. A perspectiva estado-centrista nos estudos sobre segurança acabaria assim por reforçar o estatismo, de modo a ignorar outros objetos referenciais e agentes de segurança que não seja o Estado (BILGIN, 2002, p. 102).

Este posicionamento não é uma exclusividade dos (neo)realistas, conforme apontam Buzan \& Hansen (2009, p. 38), sendo possível identificar outras correntes teóricas adotando posições semelhantes nos estudos sobre segurança em relação à condição do Estado como seu principal objeto referencial. Nesse sentido, podem ser agregados a esse grupo os chamados construtivistas convencionais (cf. THOMAS, 2000; KATZENSTEIN, 1996; PRICE, 1995). Estes persistem em debater questões de segurança com foco em fatores militares e estado-cêntricos - inclusive em relação aos objetos referenciais -, porém a partir de explicações fundamentadas em aspectos ideacionais, numa tentativa de avançar em relação às explicações (neo)realistas e (neo)liberais que se baseiam em aspectos materiais (cf. BUZAN, HANSEN, 2009, p. 192-197).

As abordagens desenvolvidas por alguns autores pós-colonialistas também consideram o Estado como o principal objeto referencial da segurança (cf. BARKAWI, LAFFEY, 2006; NIVA, 1999; AYOOB, 1997). Os autores que destacam tal aspecto, apontam para as especificidades dos países de "Terceiro Mundo", em especial, a trajetória distinta dos Estados não-ocidentais e a relação de desigualdade econômica, social e militar recorrentes entre o Ocidente e o resto. Diante disso, acaba sendo reforçada a concepção de que os países do "Terceiro Mundo" são "falidos" ou "subdesenvolvidos", o que implica na insistência quanto à necessidade de um Estado forte, e, portanto, o imperativo de mantê-lo como objeto referencial das ações no campo da segurança (cf. BUZAN, HANSEN, 2009, p. 200-202). 
Existem diferentes correntes teóricas que consideram outros objetos referenciais, porém, vale ressaltar, isso não significa que desconsiderem por completo a necessidade de perseverar na proteção do Estado, apenas deixam de tê-lo como principal ou único fator que merece atenção nos estudos e práticas sobre segurança. Dentre os autores da abordagem teórica denominada Estudos de Paz, Galtung (1969) evidencia com o conceito de violência estrutural a necessidade de conceber a proteção de coletividades humanas como foco da segurança - relegando o indivíduo e o Estado ao segundo plano -, em decorrência da atenção que dá aos riscos potenciais dos conflitos sub-estatais e às ameaças deflagradas pelo Estado e por estruturas imperialistas/econômicas globais (cf. BUZAN, HANSEN, 2009, p. 123-129). Por outro lado, a segurança humana e a social são tomadas como principal objeto referencial dos autores da Teoria Crítica, como Both (2007) e Bilgin (2005), que compartilham a preocupação com o "povo" ou as "pessoas" de modo geral, em vez dos Estados, sempre enaltecendo o compromisso em fazer assim com que a segurança seja entendida como vetor da construção de uma sociedade justa e de uma ordem mundial pacífica (cf. BUZAN, HANSEN, 2009, p. 205-208).

Os autores da teoria feminista também se contrapõem à visão de que 0 Estado deve ser o principal objeto referencial (TICKNER, 2001; SCOTT, 1992; ENLOE, 1983). A abordagem multidimensional e emancipatória que defendem alguns de seus autores em relação à segurança está comprometida em tratar da violência, tanto física como estrutural, que as mulheres e determinados grupos sofrem, devendo esses figurarem como o alvo principal das medidas protetivas, nos diversos níveis de governança político-institucional existentes (cf. BUZAN, HANSEN, 2009, p. 205-208). Os pós-estruturalistas, sempre defendendo a possibilidade de repensar conceitos, pressupostos e justificativas, também contestam a visão estado-centrista, inclusive aquilo que deve ser considerado seu principal objeto referencial (CAMPBELL, 2002; DER DERIAN, 2005; WEBER, 1998). A proteção de determinadas coletividades e valores, assim como os indivíduos de modo geral, tornam-se o centro da atenção, a partir da desconstrução de uma ampla gama de discursos e práticas legitimadoras, de concepções sobre segurança que privilegiam certos valores e identidades, 
pretensamente, prevalentes e incontestáveis (cf. BUZAN, HANSEN, 2009, p. 218-221).

Do ponto de vista das correntes teóricas, a ampliação dos objetos referenciais da segurança talvez encontre seu ápice na abordagem construtivista da Escola de Copenhagen, a partir da teoria da securitização (BUZAN et al., 1998; WÆVER, 2007). A securitização fundamenta-se na análise dos "atos de fala", num processo que envolve um ator securitizador, o qual identifica uma ameaça existencial a um objeto a ser protegido e reivindica para tal circunstância a condição de um problema de segurança, que pode ser ou não admitida pela audiência a qual se dirige. Nesses termos, a princípio admite-se que qualquer temática pode se tornar uma questão de segurança, envolvendo uma variedade de atores, múltiplas formas de ameaça e diversos objetos referenciais a serem alvos das medidas de segurança.

A depender do caso, pode-se considerar como objeto referencial desde o indivíduo, grupos sociais e a humanidade como um todo, até o meio ambiente humano e natural, recursos naturais esgotáveis, infraestruturas críticas, instituições político-governamentais, financeiras, mercantis ou industriais, um conjunto de países, regiões, continentes ou o mundo como um todo (BUZAN et al. 1998, p. 35-42). Diante desse posicionamento, os autores da Escola de Copenhagen são conhecidos como defensores do "aprofundamento" do conceito de segurança, dada a concepção defendida, em tese, de que podem existir inúmeros objetos referenciais conforme o contexto socialmente construído (cf. BUZAN, HANSEN, 2009, p. 212-217).

As perspectivas contestatórias defendidas por essas últimas correntes teóricas das Relações Internacionais supracitadas contribuíram para 0 surgimento das abordagens sobre objetos referenciais apresentadas nas seções seguintes. No entanto, não são dirigidas apenas ao estatismo e ao estadocentrismo identificados na concepção sobre os objetos referenciais da segurança. Em termos mais amplos, as variações identificadas sobre aquilo que deve ser protegido implicam numa contestação dos quatro "Ss" referentes às iniciais da tradução em inglês de Estado, Estratégia, Ciência e Status Quo, 
fatores que costumam orientar o ponto de vista tradicional e dominante nos estudos de segurança, o qual, grosseiramente, pode ser resumido nos argumentos defendidos pelo realismo político (WILLIAMS, 2008, p. 3).

Em primeiro lugar, o foco estaria em contrapor a condição dos Estados (state) nas perspectivas (neo)realistas tanto como os agentes mais importantes como os objetos referenciais basilares na política internacional. Em segundo lugar, o enfoque recai na crítica à estratégia (strategy) em decorrência das preocupações intelectuais e práticas dos autores girarem, fundamentalmente, em torno da melhor forma de empregar a ameaça e o uso da força militar. A contestação do caráter científico (scientific) emerge da pretensão (neo)realista de estabelecer um conhecimento autêntico e objetivo - em oposição à mera opinião -, adotando métodos que imitam as ciências naturais, como a física e a química, sendo assim possível admitir o estudo da segurança de forma científica. Por fim, refletiriam uma confrontação à preocupação implícita e conservadora de preservar o status quo, em que as grandes potências e a maioria dos acadêmicos compreendem as políticas de segurança como um meio para se evitar a mudança radical e revolucionária da sociedade (WILLIAMS, 2008, p. 3).

A seção seguinte apresenta outra abordagem sobre o assunto, desta feita, evidenciando a preocupação de se colocar o ser humano como ponto fundamental na discussão sobre "o que" ou "a quem" proteger a partir de iniciativas na área da segurança.

\section{A SEguRANÇA humana E A PREVALÊnCIA do INDIVÍdUO COMO OBJETO REFERENCIAL}

A gênese dessa abordagem que enfoca a ideia de "segurança humana", se evidencia no final dos anos 1970, quando alguns estudiosos começaram a contestar a noção do Estado como objeto referencial apropriado, e discutiam que as abordagens convencionais falharam em captar uma diversidade de atores e agendas no cenário mundial, as quais representariam uma variedade de 
ameaças aos cidadãos e aos regimes. Durante os anos 1980, e no início de 1990, tais reflexões ganharam destaque considerável e um novo pensamento começou a se firmar entre os formuladores de políticas em vários países sobre segurança (HENK, 2005, p. 92).

O termo segurança humana foi empregado pela primeira vez num documento do Programa das Nações Unidas para o Desenvolvimento (UNDP), intitulado "Human Development Report 1993", cuja explicação sistematizada ocorreu na versão seguinte do relatório. Neste documento fica clara a crítica à concepção tradicional, que toma como objeto referencial da segurança o Estado:

O conceito de segurança tem sido durante muito tempo interpretado de forma restritiva: a segurança do território contra agressões externas, ou como a proteção dos interesses nacionais através da política externa ou como a segurança global contra a ameaça de um holocausto nuclear. Ela tem sido mais relacionada com os Estadosnação do que com as pessoas (UNDP, 1994, p. 22).

O mesmo relatório aponta que uma "definição mais explícita" sobre segurança humana envolve dois aspectos fundamentais: a segurança contra ameaças crônicas como fome, doença e repressão; e a proteção contra a interrupção súbita e dolorosa dos padrões de vida diária. A partir daí são estabelecidos novos parâmetros na compreensão da segurança: (1) a transição do conceito estreito de segurança nacional ao conceito abrangente de segurança humana; (2) a mudança nos esforços exclusivamente voltados à segurança territorial para a uma incidência maior na segurança das pessoas; e, (3) a modificação da visão de segurança através de armamentos, para a segurança constituída através do desenvolvimento humano sustentável (UNDP, 1994, p. 23-24).

Do ponto de vista do desenvolvimento de uma teoria e metodologia próprias dos estudos sobre segurança humana, de acordo com Hampson (2008, p. 241), existe uma nítida dificuldade de identificar uma uniformidade ou coesão particular que permita Ihes atribuir especificidade. Entretanto, é possível observar que a tentativa sistemática de a desenvolver envolve um nítido abandono das várias escolas realistas de teorização em Relações Internacionais. As palavras de Newman (2001, p. 240-249) vão exatamente no 
mesmo sentido, ao destacar que a "Segurança humana não é uma teoria; ela é apoiada em teorias - aquelas científicas sociais".

Trata-se, portanto, de uma perspectiva revisionista em razão da nova agenda de questões a serem confrontadas, o que implica também em um novo olhar sobre o objeto referencial da segurança. $O$ mundo entra assim numa nova era em que o conceito de segurança passa por mudanças, as quais compreendem: a segurança das pessoas, não apenas dos territórios; a segurança dos indivíduos, não somente das nações; segurança através do desenvolvimento, não exclusivamente através das armas; e, a segurança de todas as pessoas em qualquer lugar (HAQ, 1995, p. 115). Diante dessa mudança de percepção, evidencia-se que a relação entre indivíduos e Estado nem sempre é sinérgica:

\begin{abstract}
A relação entre indivíduos e o Estado pode ser positiva, neutra ou negativa: o Estado pode melhorar a segurança dos cidadãos individualmente e grupos através da provisão de lei e ordem, oportunidades econômicas ou instalações voltadas ao bem-estar social, por exemplo, ou da mesma forma, prejudicar a segurança individual por infringir os direitos humanos básicos ou tolerar níveis nocivos de poluição industrial (RAHMAN, 2009, p. 6).
\end{abstract}

É importante destacar que a perspectiva centrada na segurança humana, pelo fato de confrontar a centralidade do Estado como seu objeto referencial, não estabelece propriamente uma relação antagônica com a segurança estatal, nem tão pouco ignora o papel do Estado como agente fundamental da segurança humana. Nesse sentido, Bajpai (2000, p. 37) adverte que a ideia de segurança humana não releva a segurança estatal, mas a considerada como algo equivalente, tanto porque a segurança do Estado também representa a segurança das pessoas, bem como o ente estatal pode ser considerado o provedor da segurança para os cidadãos. A segurança do Estado seria concebida como um meio para a consecução da segurança humana, mas não seria o seu fim maior, pois apenas a segurança das pessoas pode ser o seu objetivo legítimo.

Shinoda (2004, p. 12-13) também lembra que o "Human Development Report" identifica a ameaça de outros Estados como ameaças contra a 
segurança humana, incorporando elementos "tradicionais" da segurança dentro do contexto da segurança humana, e rejeitando que haja oposição entre as duas perspectivas. Além disso, observa que, embora a segurança humana não seja estado-centrista, os agentes responsáveis pela segurança são entes governamentais e não-governamentais, não sendo defendida fora da esfera dos Estados, mas dirigidas a estes, com a intenção de que ajustem suas políticas às novas necessidades.

Não obstante a importância do Estado, Alkire (2003, p. 33) chama atenção para o fato de que a ampliação dos estudos e práticas nessa seara pode implicar numa reconfiguração na atuação dos atores responsáveis pela garantia da segurança, uma vez que essa problemática se insere num universo de ações concorrentes entre diferentes níveis de poder. A reconfiguração levantaria questões fundamentais, a ponto de algumas ameaças globais à segurança humana, por exemplo, serem concebidas como mais bem tratadas por instituições internacionais, por organizações não-governamentais (ONGs) e por grupos locais e regionais. Em certa medida, tal posicionamento surge como contraponto ao estatismo.

Nesse debate sobre a prevalência do Estado nas análises sobre segurança, Walker e Maxwell (2008) defendem a percepção do que denominaram de "sistema humanitário internacional", o qual possuiria uma lógica particular de responsabilização, fluxo financeiro e contexto causal, que permite compreender o papel das instituições e atores globais na conformação das ações humanitárias existentes. A possibilidade de descentralização presente na segurança humana estaria implícita nos desafios inerentes à efetivação da intervenção humanitária, em especial, as medidas relativas à legitimidade e capacidade de atuação das instituições internacionais através de meios militares ou não militares, quando há violações graves aos direitos humanos.

Nesse mesmo sentido, Thomas (2001, p. 174) alerta que "Em última análise, a segurança humana exige diferentes estratégias de desenvolvimento das atualmente oferecidas por instituições de governança global, estratégias que tenham redistribuição em seu núcleo", de modo a melhor refletir as preocupações da maioria 
dos países do mundo e dos cidadãos. $\mathrm{E}$, isso significaria que as ações em segurança humana deveriam se concentrar em estratégias de desenvolvimento social, que imponham maior pressão sobre os países ricos em vez dos pobres, que incentivem orçamentos equilibrados que não abalem a vida das pessoas, e que deem voz muito maior às nações pobres.

As posições defendidas pelos adeptos da segurança humana não estão isentas de críticas. Algumas dessas são evidenciadas por Buzan (2000, p. 8), quando afirma que o indivíduo como objeto referencial não seria uma inovação, já que os direitos humanos há muito tempo têm sua abordagem centrada nesse elemento. Complementarmente, ao considerar a humanidade como foco, isso implicaria numa perspectiva demasiada ampla e vaga para ter apelo popular, diferentemente das preocupações que consideram preocupações coletivas, que são captadas entre pessoas que compartilham alguma identidade comum.

Para Khong (2001, p. 234), o caráter universalista da segurança humana retira muito do seu conteúdo de política produtiva, isto porque não oferece uma orientação prática, seja para definir prioridades ou para dirimir a insegurança. A bem-intencionada tentativa de securitizar o ser humano levaria a três grandes armadilhas: (1) gera falsas prioridades, pelo desafio de estabelecer um critério específico quando todos os indivíduos do planeta tornam-se objeto de preocupação; (2) suscita falsas esperanças, pois a securitização do bem-estar do indivíduo não significa, efetivamente, melhoria na situação do reprimido; (3) perpetua falsas premissas causais, pelas possíveis inconsistências de raciocínios ou conclusões que derivam da ideia de que a segurança humana coloca as pessoas em primeiro lugar, e que sua proteção é essencial para a promoção e manutenção da paz e da segurança internacionais (KHONG, 2001, p. 231236).

Considerando como referência a crítica aos quatros "Ss" da visão tradicional, mencionados na seção anterior, percebe-se que ao estabelecer como foco das ações de segurança o ser humano, não se modifica apenas a percepção sobre o objeto referencial. Em nítida contestação ao estado-centrismo (state), apresenta-se também uma discussão sobre a centralidade do ente estatal como promotor ou ator principal na promoção da segurança, concorrendo com outros como as organizações internacionais, em razão, por exemplo, da peculiaridade que certas questões demandam. A repercussão também se verifica no "S" de strategy na medida em que as preocupações 
deixam de girar em torno da melhor forma de empregar a força militar, para se manifestar em questões como o desenvolvimento e o bem-estar dos seres humanos. Complementarmente, observa-se ainda o caráter revisionista da abordagem, uma vez que o foco na proteção do ser humano promove, perceptivelmente, uma nova forma de conceber e tratar diversos aspectos relativos à segurança, do ponto de vista analítico e normativo, confrontando o compromisso de perpetuação do "S" de status quo, atribuído à visão tradicional.

Na próxima seção será possível apresentar a discussão em torno da definição da sociedade como elemento a ser protegido pelas políticas de segurança.

\section{A SOCIEDADE EM EVIDÊNCIA NAS QUESTÕES CONCERNENTES À SEGURANÇA}

Os estudos sobre segurança societal (societal security), como outras visões não tradicionais, emergem em meio às transformações ocorridas a partir da década de 1980, quando são envidados esforços analíticos para compreender a ordem mundial que se testemunhava com o fim da Guerra Fria e o aprofundamento da integração mundial com o processo de globalização. A percepção era de que, enquanto os perigos de confronto militar entre grandes potências diminuiriam, ameaças diretas em direção à coletividade aumentavam, impulsionando a mudança da característica geral das ameaças à segurança, inclusive considerando novos objetos referenciais.

O desenvolvimento do conceito de segurança societal é atribuído ao livro de Wæver, Buzan, Kelstrup e Lemaitre (1993), no qual sugere-se que fatos ocorridos na Europa evidenciavam que as preocupações sociais se tornaram cada vez mais importantes em comparação com os problemas relacionados à soberania do Estado. No entanto, as justificativas também podem ser encontradas em outras partes do mundo (ROE, 2010, p. 115). Na Europa Ocidental, a União Europeia (UE) impelia a lealdade política cada vez mais para 
cima (nível da UE) ou para baixo (nível dos países), enfraquecendo a ligação entre Estado e sociedade. Na Europa Oriental, o colapso dos países socialistas mostrou o conflito em aderir ao Estado (lugoslávia Federal) ou a grupos-étnicos (sérvios, croatas e bósnios). Em outros lugares, a importância da segurança societal reflete-se na luta de grupos, como palestinos e curdos, privados de um Estado próprio e considerados como obstáculo para a estabilidade do Estado (ROE, 2010, p. 115).

A segurança societal pode ser definida como "[...] a capacidade de uma sociedade permanecer com suas características essenciais, em condições mutáveis e diante de ameaças reais ou possíveis", de modo que seja possível manter "[...] condições aceitáveis para a evolução de padrões tradicionais de língua, cultura, associação, identidade e costumes religiosos e nacionais" (WÆVVER et al., 1993, p. 23). O conceito de segurança societal, em termo gerais, torna possível compreender em que condições a sociedade, e seus diferentes segmentos, podem se tornar atores políticos significativos (BILGIN, 2003, p. 212). Os defensores dessa abordagem procuram fazer perceber assim que a segurança societal não é uma simples extensão da segurança estado-cêntrica, posto que os estamentos estatais, nacionais e sociais, nem sempre encerram em si a concepção de unidade e convergência.

Uma das principais críticas ao modelo tradicional proposta pelos defensores da segurança societal enfatiza que os estudos da área habitualmente dão pouca atenção àquilo que ocorre internamente nos países, que podem resultar em ameaças mais graves do que aquelas externas (THEILER, 2010, p. 106-108). Em geral, a segurança societal tem como foco dilemas relacionados a questões como a etnicidade, nacionalismo e identidades religiosas, e casos em que o Estado e as sociedades não desenvolvem uma relação sinérgica, como, por exemplo, no caso em que minorias ou grupos nacionais são ameaçados por "seu" Estado (WÆVER et al., 1993, p. 186; BUZAN, 1991, p. 19). A partir da análise da segurança societal é possível discernir como as identidades sociais podem surgir independentemente do Estado, e em reação à identidade que o governo pretende enfatizar como sendo aquela que constrói a unidade nacional (BILGIN, 2003, p. 212-213). 
Os estudos e práticas fundamentadas na perspectiva de tomar certos valores e identidades sociais de grupos ou etnias como objeto referencial revelam importante contribuição da perspectiva construtivista como elemento teórico-analítico no campo da segurança (cf. REUS-SMIT, 2005; MCSWEENEY, 1999). A razão para tal baseia-se, em especial, na perspectiva de que tanto os aspectos diferenciadores como a língua e os costumes, assim como o repositório de significados compartilhados entre os seus membros, são socialmente construídos e não predeterminados. Consequentemente, a identificação dos conflitos, ameaças, identidades, preferências e interesses na esfera da segurança, visando a proteção de um determinado agrupamento social, devem levar em consideração as diferentes características que se estabelecem num determinando ambiente coletivo. Da mesma forma seriam as análises ou ações sobre segurança.

Diversos estudos que envolvem segurança societal demonstram a contribuição do construtivismo nesse sentido. Gagnon (2006) utilizou tal perspectiva para entender a securitização relativa aos movimentos anti-União Europeia ou anti-imigrantes da Europa Ocidental, para com a Europa Central e Oriental. No mesmo sentido, Roe (2005) desenvolveu suas análises sobre questões de segurança no separatismo na ex-lugoslávia e na União Soviética.

Algumas questões suscitadas pela teoria crítica são igualmente relevantes para compreender o que acontece quando a proteção de valores e identidades sociais prevalece como objeto referencial da segurança (cf. BOTH, 2007; BILGIN, 2008). A sua principal contribuição talvez seja o de evidenciar que os debates sobre segurança estão inseridos nos jogos de interesse e nas disputas pelo poder entre os atores políticos, seja na esfera nacional ou internacional. Além disso, a teoria crítica instiga 0 analista a ampliar a compreensão sobre a segurança e as ações no seu domínio, pois estimula a percepção de que há uma variedade maior de ameaças ou problemas que podem vir a afligir os diferentes objetos referenciais.

Nesse sentido, Bilgin (2008, p. 98-100), por exemplo, acredita que se pode assim apontar de forma mais adequada as ameaças vividas efetivamente por 
"homens" e "mulheres" - bem como os grupamentos sociais - possibilitando a mudança de foco da segurança para algo diferente da lógica da soma zero, do estatismo e do militarismo, as quais dominam a agenda tradicional. Por outro lado, oferece ainda a oportunidade de questionar a centralidade dos líderes políticos na determinação do que deve ou não ser considerada uma temática de segurança, bem como a pertinência das definições sobre segurança dentro de um quadro de relações conflitivas entre os atores envolvidos ou o foco no emprego de medidas emergenciais para superar as adversidades.

De certa forma, a segurança societal confronta o estatismo, alertando quanto à percepção de que o Estado nem sempre age como principal agente da segurança. Em certas circunstâncias, é necessária a interveniência de terceiros em conflitos étnicos, não só visando a garantia de direitos pessoais, mas também aqueles de ordem social, como ocorreu nos casos da Somália (1991-1994) e de Ruanda (1990-1996), em que a Organização das Nações Unidas interveio (NALBANDOV, 2009).

As palavras de Saleh (2010, p. 234) são bem precisas sobre as possíveis interações negativas que podem emergir da relação entre os dois atores coletivos, particularmente, enfatizados pela abordagem da segurança societal:

\begin{abstract}
A tensão entre o Estado e seus subgrupos sociais prejudica, por exemplo, a integridade territorial e autonomia política do Estado, bem como a identidade da sociedade. Como argumentado antes, Estados sobrevivem mantendo sua soberania e a sociedade sobrevive mantendo a sua identidade. Como resultado, assim como o Estado, os grupos sociais podem defender a sua identidade pela militarização de seus membros. Em outras palavras, os confrontos sociais desestabilizam a segurança política e solapam a legitimidade do Estado.
\end{abstract}

As críticas à percepção sobre o objeto referencial da segurança são discutidas por inúmeros autores. Cabe ressaltar, inicialmente, que os fundadores do conceito de segurança societal já estabelecem limites quanto à amplitude do significado e do papel dessa perspectiva nos estudos sobre segurança, conforme fazem entender Wæver et al. (1993, p. 27):

A questão da segurança societal é uma novidade no campo dos estudos sobre segurança, e em alguns pontos essenciais vai de 
encontro com os procedimentos e as premissas essenciais do campo. Mas nós não oferecemos a segurança social como o novo, como teoria alternativa voltada a substituir a segurança clássica ou os estudos estratégicos. Nosso objetivo é certificar-se de que a nova agenda é cuidadosamente inserida na teoria da segurança existente. Queremos ser mais precisos quanto for possível, para que as consequentes revisões tenham de ser feitas na teoria de segurança, e que, na verdade, a mesma continue.

Para Bilgin (2003, p. 213) a segurança societal tem um problema basilar relativo à avaliação das reivindicações de identidades concorrentes, presentes em diferentes grupos nacionais, as quais dificultam, por exemplo, definir quem são os agressores e as vítimas diante de ameaças à identidade como causa do conflito. O autor cita a incapacidade dessa abordagem dar respostas ao conflito entre sérvios, croatas e bósnios. Em segundo lugar, destaca que quando a segurança societal é usada para orientar a política, a sociedade torna-se reificada e tratada como constante e imutável.

Outra crítica traz à baila o fato de as discussões sobre sociedade se dirigem, principalmente, ao problema da identidade. McSweeney (1999, p. 72) observa que em vez de assumir que a identidade é o único valor vulnerável à ameaça, intuitivamente, é possível evidenciar também um gama de outros valores em perigo, com destaque para aqueles relacionados ao bem-estar econômico. Já Bilgin (2003, p. 213) observa que "Os conflitos em torno da identidade não são a causa, mas o resultado de um processo através do qual conflitos de interesses econômicos e políticos são reformulados e apresentados em termos de identidade". Mesmo diante de tais contestações, é difícil negar a contribuição da perspectiva erigida a partir da ideia de segurança societal em relação à visão tradicional, a qual está baseada em importantes mudanças teóricas e práticas vividas no início da década de 1990 nos estudos em Relações Internacionais.

Diante do exposto, pode-se ressaltar a ascensão das teorias construtivista e crítica como paradigmas explicativos no âmbito da segurança, propugnando diferentes referenciais teórico-analíticos e contestando a pretensão reivindicada pelos (neo)realistas de ser o único modelo ao qual pode ser atribuído caráter efetivamente científico (no caso, o "S" de science). Da mesma forma, o componente estratégico (strategy) da abordagem tradicionalista é contestado, quando se percebe que as necessidades a serem garantidas nesse contexto não 
se restringem a questões de ordem militar, mas outros tantos que derivam da existência de diferentes conglomerados sociais com diferentes identidades, demandas, interesses e preferências, que vão desde o nível local ao global. A conformação da segurança societal, nesses termos, leva ao questionamento de outro paradigma do modelo tradicional de concepção da segurança (no caso, o "S" de state), já que essa ideia se põe como um desafio à primazia da lealdade para com a segurança coletiva do Estado. Os aspectos ora mencionados contribuem para evidenciar outro aspecto revisionista dos estudos e das práticas no campo da segurança quando se considera a sociedade como seu objeto referencial, não assumindo o compromisso em fazer prevalecer pontos de vistas conservadores atribuídos aos autores tradicionalistas (no caso, o "S" de status quo).

A seguir é apresentado mais um enfoque, evidenciando agora a necessidade de se colocar o meio ambiente como elemento essencial na discussão sobre objeto referencial da segurança.

\section{AS DIMENSÕES NATURAIS E hUMANAS NO DEBATE SOBRE A SEGURANÇA AMBIENTAL}

O meio ambiente também é tido como objeto referencial nos estudos sobre segurança, o qual se constitui como um dos fundamentos da ideia de "segurança ambiental". Por volta do final dos anos 1980 e início de 1990, a segurança ambiental tornou-se um amplo movimento, alcançando influência considerável na conformação da agenda de pesquisas empíricas e começando a moldar a política na esfera interna e externa dos Estados (DEUDNEY, 2006, p. 232).

Conforme esclarece Brauch (2005, p. 18-19) é possível identificar quatro fases da investigação ao longo do tempo sobre segurança ambiental. A primeira compreende as décadas de 1970 e 1980, quando as pesquisas focavam no impacto ambiental das guerras e na reformulação do conceito de segurança, incluindo uma nova gama de ameaças à segurança e a aceitação de que seu objeto referencial já não era simplesmente o Estado - já que poderia variar níveis acima e abaixo deste. A segunda 
fase refere-se à década de 1990, marcada por pesquisas empíricas, as quais enfocavam na interação entre fatores como transformações globais e degradação, escassez e estresses ambientais, e como tais fatores resultariam em conflito ou cooperação.

A terceira fase, em meados da década de 1990, quando os estudos comparativos e o aprofundamento conceitual foram lançados por muitos grupos de pesquisa, os quais empregavam técnicas de análise, representação e simulação da evolução espaço-temporal de sistemas ambientais, explorando esforços de gestão, focando na potencialidade de conflito decorrente da utilização de recursos, nas deficiências do aparelho estatal e em desastres relacionados às mudanças globais. A quarta fase refere-se às pesquisas desenvolvidas a partir do século XXI, voltadas a investigar fatores naturais estruturais (alterações climáticas, água, solo), dimensões humanas das mudanças ambientais globais (população urbana e sistemas rurais), estudos estes baseados na expertise das inúmeras ciências que envolvem tais fatores/dimensões.

A defesa da perspectiva que tem a segurança centrada no meio ambiente é feita de modo bastante contundente por Hughes (2004, p. 29) ao afirmar que "Em certo sentido, o meio ambiente natural em si é o mais importante objeto referencial da segurança devido ao ataque sistemático feito pela humanidade, e por responder como uma espécie de impositor de ameaças finais à sobrevivência humana". Por outro lado, Eckersley (1992) não só ressalta que o adequado objeto referencial da segurança deveria ser o meio ambiente, e, de modo específico, o ecossistema global, como também que a maior ameaça a sua existência seria o próprio ser humano.

A definição de Buzan (1991, p. 19-20) é dada nos seguintes termos: "[...] a segurança ambiental diz respeito à manutenção do local e da biosfera planetária, assim como o sistema essencial de apoio a partir dos quais todos os outros empreendimentos humanos são dependentes". Esta definição estabelece a compreensão de que o meio ambiente - enquanto objeto referencial - incorpora uma dimensão mais ampla, a qual não se restringe unicamente à preservação dos ecossistemas, mas também à sobrevivência dos seres humanos. 
A propósito dessa constatação, vale observar as questões frequentemente investigadas no âmbito da segurança ambiental, indicada por Buzan et al. (1998, p. 74-75): distúrbios nos ecossistemas (alterações climáticas, perda de biodiversidade, desmatamento); problemas de energia (energia nuclear, transporte de petróleo, escassez e distribuição desigual); problemas da população (crescimento populacional, consumo desenfreado, más condições de saúde); problemas alimentares (consumo excessivo, perda de solos férteis e recursos hídricos); problemas econômicos (produções insustentáveis, quebras cíclicas e assimetrias estruturais); guerra civil (guerras por danos ambientais e violência relacionada com a degradação ambiental).

Ante a agenda ora descrita, De Wilde (2008, p. 598) chama atenção para o fato de que "A primeira característica desta lista é que ela mostra uma distinção entre as ameaças ao ambiente, que leva à securitização do próprio ambiente, e as ameaças do ambiente, que leva à securitização das pessoas e das sociedades que dependem dela". Além disso adverte que em questões concernentes à segurança ambiental, o objeto referencial é explicitamente o meio ambiente, o qual, no entanto, deve ser compreendido de modo mais amplo, pois ao lado dos elementos naturais que conformam a biosfera, emerge igualmente a preocupação geral com a preservação das atuais condições de existência da civilização humana.

A caracterização ora sugerida à segurança ambiental também é defendida por Brauch (2005, p. 15), que ressalta a existência de uma complexa interação entre processos na "ecosfera" e "antroposfera", que pode ser compreendida como um "hexágono da sobrevivência", composto por desafios a três recursos naturais (ar, terra e água) e três desafios de ordem social (população humana, sistemas urbanos e sistemas rurais). Nesses termos, do ponto de vista de Brauch (2011, p. 99):

O meio ambiente deve ser considerado tanto como uma causa e como um objeto específico de ameaças, desafios, vulnerabilidades e riscos provocados pelas mudanças ambientais globais, pela poluição ambiental e pelos perigos naturais relacionados à segurança "objetiva" e "subjetiva" dos seres humanos e da humanidade (segurança humana), de grupos sociais (segurança societal), de Estados-nação (segurança nacional), e de associações de Estados (segurança europeia) [e] macrorregiões (segurança regional), e em alguns casos extremos, tais como "a mudança climática abrupta", [...] também para a Terra (segurança global). 
Os seis desafios que compõem o "hexágono da sobrevivência", segundo o autor, podem interagir de diferentes maneiras e contribuir para a escassez ambiental de inúmeros recursos naturais, bem como levar - sob certas condições socioeconômicas contextuais - a resultados conflituosos em nível nacional ou supranacional.

Quanto às críticas relativas à pertinência de atrelar questões ambientais às práticas de segurança, Deudney (2007, p. 130-133) baseia a sua em três aspectos, os quais buscam evidenciar argumentos tradicionalistas sobre segurança. Inicialmente, seria incorreto pensar a degradação ambiental como ameaça à segurança, porque o foco tradicional - violência interestatal - tem pouco em comum com problemas ou soluções ambientais, pois estes estão relacionados, principalmente, à cooperação, tecnologia, transparência e criatividade. Em seguida, destaca que ao adotar o discurso de que todas as pessoas, lugares e "coisas" dentro e fora do Estado encontram-se em potencial ameaça, isso parece fragilizar a capacidade de mobilização nacional voltada a criar consciência e ação ambiental em nível doméstico. Por fim, ressalta que ainda carece de maior comprovação a percepção de que degradação ambiental, efetivamente, constitui-se como causa de guerras civis ou conflitos interestatais.

Vale ressaltar uma preocupação levantada pela World Conservation Union, quanto ao temor de que a propagação da segurança ambiental possa levar à militarização das questões ambientais, em vez da "ecologização" da segurança. Em vez das instituições militares se submeterem à mudança, para refletir sobre novas prioridades de segurança, aquelas seriam mais propensas a cooptar e enfraquecer os fatores não estatais, não ameaçadores e a ética cooperativa das emergências ambientais. Complementarmente, enfatiza ainda que "Essa crítica é reforçada pela percepção de que as instituições de segurança estão à procura de novas missões para justificar seus altos níveis de financiamento da Guerra Fria" (DABELKO et al., 1998, p. 42).

Ainda assim, as questões ambientais tomam, cada vez mais, as pesquisas na área de segurança, promovendo a percepção sobre a importância de proteger o meio natural e humano. Os temas abordados são amplos, como os estudos que relacionam meio ambiente e conflitos domésticos (DE SOYSA, 2002) ou internacionais (LE BILLION, 2004), em que inúmeras questões são objeto de desarmonia ou instabilidade, como a disputa por recursos energéticos (PETERS, 2004) e hídricos (LONERGAN, 2001). Os trabalhos também exploram dilemas de outra dimensão, que sugerem opções 
políticas, as quais ligam segurança a modos ecologicamente mais sensíveis de vida (DODDS, PIPPARD, 2005), ou concernentes às demandas por modelos de governança que integram segurança ambiental e políticas dirigidas à manutenção de práticas sustentáveis (BARNETT, DOVERS, 2001).

As discussões sobre segurança ambiental evidenciam assim pressupostos que conformam o pensamento contemporâneo sobre segurança. A temática faz emergir muitas preocupações sobre a conveniência de expandir o elenco de questões concernentes à segurança - numa crítica ao "S" de strategy da visão tradicional-, e impõe questionamentos sobre quem decide o que é suficientemente grave para exigir atenção dos aparatos de Estado ou dos estudiosos de segurança agora como crítica ao "S" de state - (DALBY, 2008, p. 261). Além disso, destaquese que o discurso sobre segurança ambiental, enquanto ameaça potencial à estabilidade política, é parte de uma comunidade epistêmica que criticamente defende a reformulação e ampliação sobre o significado da segurança nacional e internacional - contestação ao "S" de status quo (HAGMANN, 2005, p. 6).

A próxima seção deste texto é voltada a apresentar como o debate sobre objeto referencial da segurança pode ser conformado visando a proteção de diferentes unidades políticas e sociais que costumam ser objeto de análise em Relações Internacionais.

\section{A ABORDAGEM SOBRE OBJETOS REFERENCIAIS DA SEGURANÇA SEGUNDO DIFERENTES NÍVEIS DE ANÁLISES}

A intenção de abordar os objetos referenciais segundo diferentes níveis de análises é "estender" os estudos concernentes à segurança, ressaltando, principalmente, as particularidades das unidades políticas específicas, para melhor compreender e explicar os fenômenos em cada estrato, bem como aperfeiçoar as práticas governamentais e intergovernamentais nos diferentes planos. Para Rahman (2009, p. 5) o fim da Guerra Fria acelerou a tendência de reformular a agenda de análise internacional sobre segurança para novos e 
amplos desafios para o bem-estar não só do Estado, mas também num nível sub-estatal que inclui indivíduos e comunidades, e, acima do Estado, da segurança nos níveis regional e até global.

No mesmo sentido, para Booth (2007, p. 30), atualmente, a "Segurança é concebida de forma abrangente, abarcando teorias e práticas relativas à múltiplos referenciais, múltiplos tipos de ameaça e vários níveis de análise". Haftendorn (1991, p. 12) ressalta que um novo paradigma da segurança deveria atender algumas demandas específicas, entre elas, a necessidade de conformála de acordo com uma perspectiva multifocal, ou seja, que não se limita a uma única área temática ou apenas a um nível de análise.

A presente perspectiva tem como uma de suas referências as ideias de Buzan (1991, 363-368), em especial, quando afirmou que o conceito de segurança só pode ser plenamente compreendido se forem integrados de forma interdependente (1) os níveis de análise e (2) os setores ou dimensões da segurança. Em relação aos níveis de análise, Buzan (1991, p. 3) esclarece que consistem na "[...] ideia de estruturar a teoria em termos de escala espacial do individual para o Estado até o sistêmico [internacional]". E, quanto aos setores/dimensões, os define como pontos de vista sobre a segurança através da lente de um tipo particular de relacionamento e atividade, compreendendo questões de ordem militar, política, social, econômica e ambiental (BUZAN, 1991, p. 3). Posteriormente, Buzan et al. (1998, p. 5-6) abordaram a questão, passando a adotar como referência cinco níveis de análise: sistemas internacionais (Onusiano, Multilateral de Comércio, Financeiro Internacional etc.), subsistemas internacionais (União Europeia, OCDE etc.), unidades (Estados, Nações, empresas transnacionais etc.), subunidades (burocracia, lobbies etc.) e indivíduos.

Buzan et al. (1998, p. 21-22) justificam sua argumentação em favor dessa perspectiva no fato de que "[...] as ameaças existentes só podem ser compreendidas em relação ao caráter particular do objeto referente em questão", da mesma forma que valores fundamentais irão "[...] variar muito entre diferentes setores e níveis de análise". A perspectiva em foco promove uma discussão 
relativa à correlação existente entre ameaças existenciais, valores fundamentais e objetos referenciais no âmbito da segurança. Nesse caso, certas questões emergem e conformam-se em setores, os quais configuram-se ou são tratados de modo específico de acordo com o objeto referencial em evidência, sendo condicionado ainda por circunstancias inerentes ao nível de análise a partir do qual se está trabalhando.

É possível verificar que, em certa situação, o objeto referencial das políticas de segurança pode ser o perfeito funcionamento do sistema multilateral do comércio (sistema internacional - dimensão econômica), a proteção militar de uma região específica como a América do Sul (subsistema internacional dimensão militar), a soberania interna de determinado país como o Brasil (unidade - dimensão política), a preservação dos costumes tradicionais de povos amazônicos (subunidade - dimensão social), ou, simplesmente, a proteção dos direitos fundamentais dos seres humanos (indivíduo - dimensão humana).

As lições de Bubandt (2005, p. 276-277) são importantes no sentido revelar que existem várias construções culturais de segurança, principalmente através de atos de fala. Nesse sentido, o citado autor propõe o conceito de "segurança vernacular", expressão que apresenta uma compreensão bastante elucidativa sobre o processo de securitização, a qual atenta para a necessidade de se levar em consideração diferentes discursos construídos em vários contextos. Daí a importância de entender a securitização como um dispositivo discursivo que evidencia (1) a concepção de comunidades específicas, (2) a evocação retórica e (3) a realização política de comunidades imaginadas em várias escalas.

Em outras palavras, trata-se de "[...] denominar a configuração específica de medos e noções de ordem, as quais são criadas em comunidades imaginadas numa escala particular, de "segurança vernacular". Neste sentido, a segurança vernacular é o resultado de atos de fala socialmente específicos que buscam estabelecer comunidades imaginadas no nível "global", "nacional" ou "local"“ (BUBANDT, 2005, p. 276-277). A "segurança vernacular" seria um termo 
apropriado para se referir à análise em vários níveis a partir da comparação de formas políticas diferentes, mas com constantes interações na gestão de ameaças e (in)certezas. Os objetos referenciais da segurança se enquadrariam nesses termos, tendo em vista a proposta de evocar e submeter à análise uma diversidade de comunidades (sistemas, subsistemas, unidades, subunidades etc.) mutuamente dependentes, e que podem atuar ou ser objeto de ameaças em várias esferas, seja global, regional, nacional ou local.

Outra relevante contribuição para compreensão do assunto é apresentada por Heurlin et al. (2006, p. 72), que analisam a segurança a partir daquilo que denomina de "seis níveis de segurança". Os mencionados níveis são classificados nos seguintes termos: Segurança para o indivíduo (segurança individual); Segurança para o grupo social, a comunidade, "Nação", entidade nacional ou étnica organizada (segurança social); Segurança para o Estado ou "Nação" (segurança nacional); Segurança para a região, não necessariamente com base na proximidade (segurança regional); Segurança para a sociedade das nações ou "sociedade internacional", constituída por todos ou a maioria dos Estados (segurança internacional); Segurança para o mundo ou o planeta como um todo (segurança global).

Em relação às ameaças vitais específicas para cada um dos seis níveis, são evidenciadas as seguintes:

\footnotetext{
Para um único indivíduo, a ameaça vital parece ser a sobrevivência física e econômica. Tem a ver com coerção e violência, em termos físicos e econômicos [...] Para a sociedade nacional é o elemento vital da identidade, que é o elemento construtivo básico da sociedade. Sem identidade não há sociedade. Para o Estado, a ameaça vital é a soberania. Sem soberania, uma entidade sócio-político não pode ser reconhecido como Estado. Para a região, a estabilidade e a coesão são os principais fatores [...] não há nenhuma organização regional sem esses elementos vitais. Para a sociedade internacional, uma ameaça à própria continuidade do sistema é o essencial, tendo em vista que as normas e regras geralmente reconhecidas podem existir numa ordem anárquica. [...] considerando o mundo como uma espécie de unidade de segurança, a sustentabilidade é considerada o fator vital exposto a ameaças (HEURLIN et al., 2006, p. 72).
} 
Cada um dos seis níveis de segurança supracitados é, ao mesmo tempo, definido como ator da segurança e como possíveis vítimas de ameaças recíprocas (objetos referenciais), na medida em que cada um pode representar uma ameaça em relação aos demais. Em meio a essa caracterização, Heurlin et al. (2006, p. 72 indagam sobre como seria possível mapear as ameaças vitais para os seis níveis de segurança, inclusive aquelas provenientes da interação conflituosa entre cada um deles. A conclusão é de que as diversas formas de ameaça existentes vitimam cada uma das unidades políticas de acordo com suas peculiaridades.

A abordagem a partir dos níveis de análise também é alvo de críticas. Para Rahman (2009, p. 8), embora as ameaças possam afetar a segurança em diferentes níveis de análise que não seja o Estado, este não deixa de ser central para o problema da segurança na política internacional, seja como protetor contra ameaças externas ou como ameaça a outros Estados. Da mesma forma, - Estado opera como garantidor da ordem interna ou como agente de instabilidade interna, que pode se espalhar para além das fronteiras, seja em nível regional ou extrarregional.

Esta crítica foi igualmente sustentada por Buzan (1991, p. 19), pois embora esse autor mencionasse outros potenciais objetos referenciais no plano sub e supra estatal, acabou por tomar a decisão de focar na segurança dos Estados. $\mathrm{O}$ argumento é de que, em primeiro lugar, a estrutura anárquica do sistema internacional torna as unidades o "[...] foco natural de preocupações sobre segurança”, e, em segundo lugar, uma vez que os Estados representam as unidades "dominante", a segurança nacional representa, portanto, a questão central. Contudo, na obra conjunta de Buzan et al. (1998, p. 37), os autores afirmam que suas posições sobre segurança não podem ser rotuladas propriamente de estado-centristas, pois o que buscam evidenciar é que os estudos sobre segurança são um "campo dominado pelo Estado".

Para McSweeney (1999, p. 62), apesar de seus vários comentários em contrário, Buzan (1991) não trabalha com três níveis de análise, mas apenas com o estatal e o internacional. No caso da dimensão doméstica o que importa, 
por exemplo, é que o Estado seja forte o suficiente para manter a ordem interna, não importando, propriamente, que sua legitimidade seja válida e justa. Em relação ao ambiente internacional, a principal preocupação seria o impacto da instabilidade interna dos Estados sobre a sua capacidade de atuação no plano externo, e nada mais do que isso. Bilgin (2005, p. 38) destaca que o fato de Buzan et al. (1998) não observarem a atuação de outros atores além do Estado, principalmente, na tomada de decisão e na implementação das ações, implica em conceber o ente estatal como protagonista ou único agente da paz e segurança, efetivamente, relevantes. Assim, pode-se afirmar que aqueles autores apenas se distanciam parcialmente de uma análise estado-cêntrica, e que atores não-estatais surgem em suas análises como tentativa de ampliar a agenda de investigação e iniciativas governamentais em segurança.

Já Booth (2007, p. 157) ressalta que a ideia de aprofundamento do conceito de segurança é frequentemente mal compreendida, uma vez que é comumente confundida com uma mudança de nível de análise, a qual partiria da segurança internacional para regional, desta última para a estatal, chegando-se à subnacional, alcançando individual, ou segundo outros possíveis arranjos. Em razão disso, tal concepção parece comprometer-se essencialmente com a ampliação das esferas de incidência dos problemas de segurança, tornando-se assim questão meramente técnica. O que leva a pensar que há quase uma conspiração para impedir que a ideia de segurança seja desmascarada como teoria política, no sentido de revelar que conceitos e práticas relativos à segurança não devem ser considerados fenômenos naturais, mas construções decorrentes de um contexto social, conformadas segundo diferentes interesses e objetivos, nem sempre evidentes.

Um dos exemplos da aplicação desse modelo de análise está no trabalho de autoria Asplund (2004) no qual o referido autor analisa o tráfico de drogas na China e na Rússia como uma questão de segurança relacionada ao crime organizado. A intenção do autor é explicar como e por que o tráfico de drogas é uma ameaça para a segurança do Estado e dos indivíduos/seres humanos, em outras palavras, esclarecer a incompatibilidade do tráfico de drogas com a segurança estatal (crime organizado, lavagem de dinheiro, corrupção e 
terrorismo) e segurança humana (tóxico-dependência, HIV/AIDS, crime, e crime violento). Destaca ainda a necessidade de entender a importância da ação concorrente do Estado e dos indivíduos no sucesso em securitizar determinada ameaça.

A segurança humana na África é examinada em diferentes contextos na obra organizada por Abass (2010), envolvendo objetos referenciais constituídos no plano continental (África), sub-regional (África Subsaariana) e estatal (Somália, Nigéria e Angola), bem como de determinados grupos sociais (mulheres e refugiados). A segurança energética é apreciada em diferentes níveis de análise, por Bahgat (2011), considerando a necessidade de proteção de diversos objetos referenciais, conforme se esteja tratando no âmbito da Agência Internacional de Energia, dos países que compõem a Organização dos Países Exportadores de Petróleo, de regiões específicas como a União Europeia, e dos desafios de certos países como China e Rússia em meio a contextos subnacionais, nacionais, regionais e globais.

A partir dos estudos supracitados e em razão de todas as questões expostas ao longo desta seção, a presente abordagem sobre objeto referencial da segurança também pode ser considerada revisionista, contrapondo-se à perspectiva conservadora dos tradicionalistas, os quais costumam tratar os fenômenos considerados com um dado, como um objeto que não precisa ser problematizado (contestação ao " $\mathrm{S}$ " de status quo). Da mesma forma que ocorreu com as abordagens apresentadas nas três últimas seções deste texto, percebe-se que considerar como objeto referencial diferentes unidades ou níveis de análise implica também em um movimento parcial de distanciamento do Estado como objeto de preocupações analíticas e normativas da segurança. $O$ que representa uma crítica ao estado-centrismo defendido pelo ponto de vista tradicional da segurança (referente ao " $\mathrm{S}$ " de state). Observa-se, novamente, que o aspecto estratégico (strategy) da visão tradicional é contraposto, já que os temas relativos ao uso da força militar também não dominam o centro das preocupações sobre segurança. As demandas e respostas variam de acordo com as diferentes ameaças e peculiaridades do objeto referencial, que pode ser 
qualquer uma das diferentes unidades políticas ou níveis de análise supracitados.

\section{CONSIDERAÇÕES FINAIS}

Uma das possíveis contribuições que podem ser extraídas do que fora exposto nas páginas anteriores para o entendimento das questões concernentes à segurança, é que os atores, desafios e objetivos envolvidos na conformação de políticas nessa seara podem ser variados, conforme seja o cenário em concreto com o qual se esteja lidando. Em razão disto, parece não se justificar um posicionamento analítico orientado a conceber os estudos e as práticas sobre segurança de uma só maneira, nem tão pouco a concepção sobre os objetos referenciais a serem tutelados.

Assim sendo, parece ser evidente a necessidade de ir além das visões (neo)tradicionais sobre segurança, as quais costumam exaltar um posicionamento mais restrito e enviesado sobre a temática; o que não significa desprezar a relevância e as contribuições analíticas derivadas de tais perspectivas dominantes. Em vez disso, a intenção é fazer perceber a necessidade premente de admitir, cada vez mais, a pluralidade de visões teóricas concernentes à segurança.

Considerar tal imperativo é relevante na medida em que se ressalta a possibilidade de conceber que os estudos e as práticas sobre segurança são socialmente construídos, e não predeterminados. Nesses termos, a abordagem prática e teórica sobre segurança, incluindo especificidades como os objetos referenciais, podem se desenvolver de acordo com as múltiplas formas que as relações sociais podem constituir, nas suas mais diferentes formas e níveis de interação. Do mesmo modo que a segurança pode variar quanto à proteção da humanidade, de um grupo social, de ecossistemas naturais, de instituições estatais, países, regiões etc., podem, igualmente, variar entre interações cooperativas ou conflituosas, tomar a forma da "política de exceção" ou "política 
normal", admitir o emprego de ações governamentais extraordinárias ou ordinárias, vincular-se a temáticas militares, políticas, econômicas ou socioambientais.

As questões discutidas neste texto em torno das diferentes perspectivas sobre "o quê" ou "quem" deve ser protegido também exaltam formas alternativas de observar os fatos sociais, contestando as tentativas de restringir as ações e percepções relativas à segurança, contribuindo ainda para o rompimento das práticas e estudos na área com percepções pretensamente hegemônicas, inclusive quanto aos objetos referenciais a serem protegidos. Dessa forma sugere-se a emancipação das formas de pensar e agir no campo da segurança, denunciando ou opondo-se às aparentes tentativas das correntes (neo)tradicionais de deslegitimar certos arquétipos na produção do conhecimento e na conformação de políticas sobre o tema.

A partir desse tipo de abordagem não-tradicional, promove-se a emergência e contribuição de várias correntes teóricas que admitem, além dos objetos referenciais, a pluralidade de atores, ações, ameaças, identidades, preferências e interesses na esfera da segurança. Complementarmente, defende-se sobretudo concepções libertadoras e transformadoras, o que significa ir para além da lógica da guerra, do estatismo, do emprego de medidas excepcionais e da consecução de objetivos predominantemente políticomilitares. As diversas formas de tratamento sobre segurança, assim como sobre objetos referenciais, parecem, portanto, ser legítimas e coerentes tanto do ponto de vista da ciência como da prática social.

A abordagem sobre objetos referenciais apresentada ao longo deste artigo leva, portanto, a outros questionamentos de ordem epistemológica e ontológica sobre segurança: Os estudos e as práticas sobre segurança são iguais em quaisquer países e regiões do planeta? Um governo se depara com um problema de segurança apenas quando se depara com uma questão de uso da força ou de natureza militar? O enfoque sobre segurança está limitado a ameaças existenciais e à quebra da ordem legal, fora do universo da política normal? As ações no plano da segurança restringem-se ao uso de medidas 
excepcionais ou incluem ações governamentais ordinárias? Os interesses, identidades e preferências concernentes à matéria são pré-determinados, ou podem mudar segundo fatores reconhecidamente relevantes para um país ou grupo de países?

A resposta a tais perguntas sobre como lidar e analisar a segurança, certamente, não hão de ser unívocas, o que implica em admitir a diversidade de concepções existentes, sobretudo, em razão da heterogeneidade de fatores que incidem sobre a temática, e considerando os mais variados aspectos possíveis que emergem das situações em concreto. $O$ ponto de partida para tanto talvez seja entender que os enfoques (neo)tradicionais são predominantes na área, mas não os únicos.

\section{REFERÊNCIAS}

ABASS, Ademola (ed.). Protecting Human Security in Africa. New York: Oxford University Press, 2010.

ALKIRE, Sabina. A Conceptual Framework for Human Security. Working Paper, Department of International Development, University of Oxford, 2003.

AMARAL, Arthur Bernardes. A Guerra ao Terror e a Tríplice Fronteira na agenda de segurança dos Estados Unidos. Dissertação (Mestrado Relações Internacionais) PUC-RIO, Rio de Janeiro, 2008.

ARON, Raymond. Paz e Guerra entre as Nações. Brasília: Editora da Universidade de Brasília/Ipri/Imprensa Oficial do Estado de São Paulo, 2003.

ASPLUND, Erik. A Two Level Approach to Securitization: An Analysis of Drug Trafficking in China and Russia. Master Thesi, Uppsala Programme of International Studies, Sweden, 2004.

AYOOB, Mohammed. "Defining Security: A Subaltern Realist Perspective". In: Keith Krause and Michael C. Williams (eds.) Critical Security Studies, Minneapolis: University of Minnesota Press, 121-46, 1997.

AZEVEDO, Thalita de Lacerda. Escola Galesa de Estudos Críticos de segurança: segurança como emancipação. Dissertação de Mestrado (Programa Pós-Graduação em Relações Internacionais) - UNESP, UNICAMP, PUC-SP, São Paulo-SP, 2009.

BAHGAT, Gawdat. Energy Security: An Interdisciplinary Approach. Cjichester: Wiley, 2011. 
BAJPAI, Kanti. Human Security: Concept and Measurement, Kroc Institute Occasional Paper 19, 2000.

BARBOSA, Luciana Mendes. Mudanças climáticas e segurança: o desafio à lógica excepcionalista do conceito de segurança. Trabalho apresentado no VI Encontro Nacional da Anppas 18 a 21 de setembro, Belém - PA - Brasil, 2012. Disponível em: <http://www.anppas.org.br/encontro6/anais/ARQUIVOS/GT15-614-645-

20120630124325.pdf>. Acessado em: 16 de maio de 2016.

BARKAWI, Tarak; LAFFEY, Mark. "The Postcolonial Moment in Security Studies", Review of International Studies, 32:2, 329-52, 2006.

BARNETT, J.; DOVERS, S. "Environmental Security, Sustainability and Policy", Pacifica Review: Peace, Security \& Global Change, 13 (2), p. 157-169, 2001.

BILGIN, Pinar. "Critical Theory". In: WILLIAMS, Paul D. (Ed.). Security Studies: an introduction. New York, London: Routledge, 2008, p. 89-102.

Regional Security in the Middle East: A critical perspective. New York: Routledge Curzon, 2005.

Individual and Societal Dimensions of Security, International Studies Review, (5), p.203-222, 2003.

Beyond Statism in Security Studies? Human Agency and Security in the Middle East, Review of International Affairs, 2 (1), p. 100-118, 2002.

BOOTH, Ken. Theory of World Security. Cambridge: Cambridge University Press, 2007.

Statecraft and security: The Cold War and beyond. Cambridge: Cambridge University Press, 1998.

BRAUCH, Hans Günter. Concepts of Security Threats, Challenges, Vulnerabilities and Risks. In: BRAUCH, H. Günter et al. Coping with Global Environmental Change, Disasters and Security. Springer-Verlag: Berlin, p.61-106, 2011.

Environment and Human Security: Freedom from Hazard Impact. InterSecTions, 2/2005, Bonn: UNU-EHS, 2005.

BUBANDT, Nils. Vernacular Security: The Politics of Feeling Safe in Global, National and Local Worlds. Security Dialogue, 36 (3), p.275-296, 2005.

BUZAN, Barry. Human security: What it means and what it entails, paper presented at the 14th Asia-Pacific Roundtable, Kuala Lumpur, 3-7, June 2000, p.1-15.

People, States and fear: An agenda for International Security Studies in the PostCold War Era. London: Harvester Wheatsheaf, 1991.

BUZAN, Barry; HANSEN, Lene (Ed.). The Evolution of International Security Studies. Cambridge: Cambridge University Press, 2009.

International Security: Widening Security. Los Angeles: Sage Publications, Vol. I, II, III e IV, 2007. 
BUZAN, Barry; WÆVER, Ole; WILDE, Jaap de. Security: A New Framework for Analysis. Boulder: Lynne Rienner, 1998.

CAMPBELL, David. "Atrocity,Memory, Photography: Imaging the Concentration Camps of Bosnia - The Case of ITN versus Living Marxism, Part 1", Journal of Human Rights, $1: 1,1-33,2002$.

CARR, Edward. Vinte anos de crise 1919-1939. Brasília: Editora da Universidade de Brasília/Ipri/Imprensa Oficial do Estado de São Paulo, 2002.

CRAVO, Teresa de Almeida. O conceito de Segurança Humana: indícios de uma mudança paradigmática?. IN: NASSER, Reginaldo Mattar. Os conflitos internacionais em múltiplas dimensões. São Paulo: Editora UNESP, 2009, p. 67-76.

DABELKO, Geoffrey; LONERGAN, Steve; MATTHEW, Richard. State-of-the-Art Review on Environment, Security and Development Co-operation. Geneva: World Conservation Union, 1998.

DALBY, Simon. Environmental Change. In: WILLIAMS, Paul D. (Ed.). Security Studies. New York: Routledge, p.260-273, 2008.

DE SOYSA, I. "Ecoviolence: Shrinking Pie, or Honey Pot?", Global Environment Politics, 2 (4), Nov. 2002, p. 1-34, 2002.

DE WILDE, Jaap H. Environmental Security Deconstructed. In: BRAUCH, Hans Günter et al (eds.). Globalization and Environmental Challenges Reconceptualizing Security in the 21st Century. Berlin: Springer Publishers, p. 595-602, 2008.

DER DERIAN, James. "Imaging Terror: Logos, Pathos and Ethos", Third World Quarterly, 26:1, 23-37, 2005.

DEUDNEY, Daniel. The Case Against Linking Environmental Degradation and National Security. In: BUZAN, B.; HANSEN, L. (Ed.). International Security. Los Angeles: Sage, v. II, 2007, p. 129-145.

DIAS, Vanda Amaro; MOTA, Sarah Carreira da; RANITO, Jovana Jezdimirovic. "Retrospectiva do conceito de segurança: alargamento e aprofundamento da agenda securitária no pós-guerra fria", Univ. Rel. Int., Brasília, v. 9, n. 2, p. 1-23, jul./dez, 2011.

DODDS, Felix; PIPPARD, Tim (eds). Human and Environmental Security: An Agenda for Change. London: Earthscan, 2005.

DUQUE, Marina Guedes. O papel de síntese da escola de Copenhague nos estudos de segurança internacional. Contexto int., 31 (3), p. 459-501, 2009.

ENLOE, Cynthia. Does Khaki Become You? The Militarisation of Women"s Lives. London: Pluto, 1983.

ECKERSLEY, Robyn. Environmentalism and Political Theory: Toward an Ecocentric Approach. New York: State University of New York Press, 1992. 
GAGNON, V. P. Jr. The Myth of Ethnic War: Serbia and Croatia in the 1990s. Ithaca: Cornell University Press, 2006.

GALTUNG, Johan. "Violence, Peace and Peace Research", Journal of Peace Research, 6:3, 167-91, 1969.

HAFTENDORN, Helga. The Security Puzzle: Theory-Building and Discipline-Building in International Security. International Studies Quarterly, 35 (1), p.3-17, 1991.

HAGMANN, Tobias. Confronting the Concept of Environmentally Induced Conflict. Peace, Conflict and Development: Issue Six, 2005.

HAMPSON, Fen Osler. "Human Security". In: WILLIAMS, Paul D. (Ed.). Security Studies: An Introduction. New York: Routledge, p. 16-43, 2008.

HAQ, M. ul. Reflections on Human Development. New York: Oxford University, 1995.

HENK, Dan. Human Security: Relevance and Implications, Parameters, p.91-106, 2005.

HEURLIN, Bertel; KRISTENSEN, Kristian; SøBY, Bertel. International Security. In: WIENER, Jarrod; SCHRIRE, Rober (Eds.). International Relations: Encyclopedia of Life Support Systems (EOLSS) - Vol III. Oxford: Eolss publishers, p.65-109, 2006.

HUGHES, Christopher W. Japan's Security Agenda: Military, Economic and Environmental Dimensions. Boulder, Colorado: Lynne Rienner Publishers, 2004.

JERVIS, Robert. Perception and Misperception in International Politics. Princenton: Princenton University Press, 1976.

JONES, Richard Wyn. "Travel Without Maps": Thinking About Security After the Cold War. In: DAVIS, M.J. (Ed.). Security Issues in the Post-Cold War World. Cheltenham: Edward Elgar, 1996, p. 196-218.

KATZENSTEIN, Peter J. The Culture of National Security: Norms and Identity in World Politics, New York: Columbia University Press, 1996.

KHONG, Yuen Foong. "Human security: A shotgun approach to alleviating human misery?", Global Governance, 7 (3), p. 213-236, 2001.

LE BILLON, P. (ed.). The geopolitics of resource wars: resource dependence, governance and violence. London: Frank Cass, 2004.

LONERGAN, S. C.. Water and conflict: Rhetoric and reality. In: DIEHL: F.; GLEDITSCH, N. P. (eds.). Environmental Conflict. Boulder: Westview, 2001, p.109-24.

MCSWEENEY, Bill. Security, Identity and Interests: A sociology of International Relations. Cambridge: Cambridge University Press, 1999.

MEARSHEIMER, J. J. . "E.H. Carr vs. Idealism: The Battle Rages On”, International Relations, 19 (2), p. 139-152, 2005. 
MESSARI, Nizar. Existe Um Novo Cenário de Segurança Internacional?. In: GÓMEZ, José Maria. (Org.). América Latina y El (Des)orden Neoliberal - Hegemonia, Contra hegemonia, Perspectivas. 1. ed. Buenos Aires: CLACSO, 2004, p. 131-149.

MORGENTHAU, Hans J. A política entre as nações. Brasília: Editora da Universidade de Brasília/Ipri/Imprensa Oficial do Estado de São Paulo, 2003.

MUNSTER, R. Van. Logics of Security: The Copenhagen School, Risk Management and the War on Terror. Political Science Publications 10/2005. Odense: University of Southern Denmark, 2005.

NALBANDOV, R. Foreign Interventions in Ethnic Conflicts. Surrey: Ashgate, 2009.

NEWMAN, Edward. "Human security and constructivism", International Studies Perspectives, 2(3): 239-251, 2001.

NIVA, Steve. "Contested Sovereignties and Postcolonial Insecurities in the Middle East". In: Weldes et al. (eds.) Cultures of Insecurity, 1999, p. 147-72.

PAIVA, lure. As dimensões militares, ambientais e econômicas da segurança energética: análise a partir dos desafios e oportunidades do Brasil no contexto internacional. Tese de Doutorado (Programa Pós-Graduação em Ciência Política) UNICAMP, Campinas-SP, 2015.

PETERS, Susanne. Coercive western energy security strategies: "resource wars" as a new threat to global security, Geopolitics, 9 (1), 2004, p. 187-212.

PRICE, Richard. "A Genealogy of the Chemical Weapons Taboo", International Organization, 49:1, 73-103, 1995.

RAHMAN, Chris. Concepts of Maritime Security: A strategic perspective on alternative visions for good order and security at sea, with policy implications for New Zealand. The Centre for Strategic Studies: New Zealand, Discussion Paper 07/09, 2009.

REUS-SMIT, Christian. Constructivism. In: BURCHILL, S. et al. (Eds.) Theories of International Relations. New York: Palgrave Macmillan, 2005, p. 188-212.

ROE, Paul. Societal Dimension of Global Security. In: BILGIN:et al. (ed.). Global Security and International Political Economy - V. I. Paris: EOLSS, 2010, p. 113-132.

Ethnic Violence and the Societal Security Dilemma. London: Routledge, 2005.

RUDZIT, Gunther. "O debate teórico em segurança internacional - Mudanças frente ao terrorismo?", Civitas - Revista de Ciências Sociais, v. 5. n. 2, jul.-dez. 2005, p. 297-323.

RUDZIT, Gunther; NOGAMI, Otto. "Segurança e Defesa Nacionais: conceitos básicos para uma análise”, Rev. Bras. Polít. Int., 53 (1), 2010, p. 5-24.

SALEH, Alam. Broadening the Concept of Security: Identity and Societal Security. Geopolitics Quarterly, 6 (4), 2010, p. 228-241.

SAINT-PIERRE, Héctor Luis. "'Defesa" ou "segurança"?: reflexões em torno de conceitos e ideologias". Contexto int., 33 (2), 2011, p. 407-433. 
"Defence and Security". In: RESDAL. A Comparative Atlas of Defence in Latin America, Buenos Aires: RESDAL, 2008.

SCOTT, Joan W. "“Experience”“, In: BUTLER, Judith; SCOTT, Joan W., Feminists Theorize the Political, London: Routledge, 1992, 22-40.

SHINODA, Hideaki. The Concept of Human Security: Historical and Theoretical Implications. In: SHINODA, H.; JEONG, W. H. (eds.). Conflict and Human Security. IPSHU English Research Report Series 19. Institute for Peace Science, Hiroshima University, 2004, p. 5-22.

TANNO, Grace. A Contribuição da Escola de Copenhague aos Estudos de Segurança Internacional. Contexto Internacional. v. 25, n. 1, p. 47-80, jan./jul. 2003.

THEILER, T. Societal Security. In: CAVELTY, M. D.; MAUER, V. The Routledge Handbook of Security Routledge Handbooks. New York: Routledge, 2010, p. 105-114.

THOMAS, Caroline. Global Governance, Development and Human Security: Exploring the Links, Third World Quarterly, 22 (2), 2001, p. 159-175.

THOMAS, Ward. "Norms and Security: The Case of International Assassination", International Security, 25:1, 2000, p. 105-33.

TICKNER, J. Ann. Gendering World Politics: Issues and Approaches in the Post-Cold War Era, New York: Columbia University Press, 2001.

UNITED NATIONS DEVELOPMENT PROGRAM (UNDP). Human Development Report 1994. New York: Oxford University Press, 1994.

VILLA, Rafael Duarte; REIS, Rossana Rocha. "A Segurança Internacional no PósGuerra Fria: Um Balanço da Teoria Tradicional e das Novas Agendas de Pesquisa", BIB, São Paulo, n 62, 20 semestre, 2006, p. 19-51.

WÆVER, Ole. "Securitization and Desecuritization". In: BUZAN, Barry \& HANSEN, Lene (Ed.). International Security. Los Angeles: Sage, Volume III, 2007, p. 66-98.

WÆVER, Ole; BUZAN, Barry; KELSTRUP, Morten; LEMAITRE, Pierre. Identity, Migration and the New Security Agenda in Europe. London: Pinter, 1993.

WALKER, Peter, MAXWELL, Daniel G. Shaping the Humanitarian World (Global Institutions). Oxon, New York: Routledge, 2008.

WALKER, R. B. J. Security, Sovereignty, and the Challenge of World Politics. In: BUZAN, B. \& HANSEN, L. (Ed.). International Security. Los Angeles: Sage, V. III, 2007, p. 146166.

WALT, Stephen M. "The Renaissance of Security Studies", International Studies Quarterly, 35 (2), 1991, p. 211-239.

WALTZ, K. N. Theory of International Politics. Reading: Addison-Wesley, 1979.

WEBER, Cynthia. "Performative States", Millennium, 27:1, 1998, p. 77-95. 
WILLIAMS, Paul D. (ed.). Security Studies: an introduction. New York: Routledge, 2008.

WOLFERS, Arnold. "National Security" as an Ambiguous Symbol, Political Science Quarterly, 67 (4), Dec. 1952, p. 481-502.

Recebido em 26 de janeiro de 2017. Aceito em 31 de Agosto de 2017. 